\title{
The Morphology and Behavior of the Endemic Malagasy Whirligig Beetle Heterogyrus milloti Legros, 1953 (Coleoptera: Gyrinidae: Heterogyrinae)
}

\author{
Grey T. Gustafson \\ Department of Ecology and Evolutionary Biology \\ University of Kansas \\ Lawrence, KS 66045, U.S.A. \\ gtgustafson@gmail.com \\ JOHANNES BERGSTEN \\ Department of Zoology \\ Swedish Museum of Natural History \\ Stockholm, SWEDEN \\ Tolotra Ranarilalatiana, Jacquelin Herisahala Randriamihaja \\ Departement d'Entomologie, Faculté des Sciences \\ B. P. 906, Université d'Antananarivo \\ Antananarivo, MADAGASCAR \\ AND \\ Kelly B. Miller \\ Department of Biology and Museum of Southwestern Biology \\ University of New Mexico \\ Albuquerque, NM 87131, U.S.A.
}

\begin{abstract}
The Malagasy endemic whirligig beetle Heterogyrus milloti Legros, 1953 is redescribed. Jumping behavior of $H$. milloti is reported here for the first time with video recordings provided. Results of a behavioral experiment conducted in the field demonstrate $H$. milloti jumps in a targeted manner in a downstream direction. The unique habitat of $H$. milloti is described in detail with both image and video of the habitat included. Morphology of H. milloti is discussed in detail, revealing symplesiomorphies with Spanglerogyrus Folkerts, 1979, characters forming transitional series between Spanglerogyrus and the Gyrininae, and features unique to $H$. milloti. The potential adaptive significance of these peculiar morphological features in association with the habitat of $H$. milloti is discussed. Finally, an argument for the necessity of conservation of this species is made, and common names in English, French, Malagasy, and Swedish for H. milloti are proposed to aid conservation efforts.
\end{abstract}

Key Words: Hydradephaga, aquatic beetles, Madagascar, conservation, jumping

DOI.org/10.1649/0010-065X-71.2.315

Heterogyrus milloti Legros, 1953 is a little known but extraordinary whirligig beetle with a striking yellow and black striped appearance (Fig. 1A). The species was originally described in 1953 by Legros, after he received a batch of Malagasy Hydradephaga from Renaud Paulian (then Deputy Director of l'Institut de Recherche Scientifique de Madagascar), containing four specimens (one male and three females) of a distinctly new taxon (Legros 1953). The original description was in French with several illustrations of some of the more interesting morphological features (Legros 1953). Legros (1953) compared Heterogyrus Legros to the known genera of the Gyrinini Latreille (then the Gyrininae), placing it within this group due to the presence of maxillary galea. Brinck (1955) was next to treat Heterogyrus. Noting the numerous unique characteristics of the genus, he decided to place it in a new monotypic tribe, but he also recognized several features uniting it with the Dineutini Desmarest (then Enhydrinae Régimbart) and the Orectochilini Régimbart (then Orectochilinae). Brinck (1955) provided a short description of the species in English as well as an improved illustration of the aedeagus of the type specimen.

Following discovery of Spanglerogyrus albiventris Folkerts, 1979, the classification of the Gyrinidae changed considerably, as Folkerts (1979) placed his new genus into the newly erected monotypic subfamily Spanglerogyrinae Folkerts 

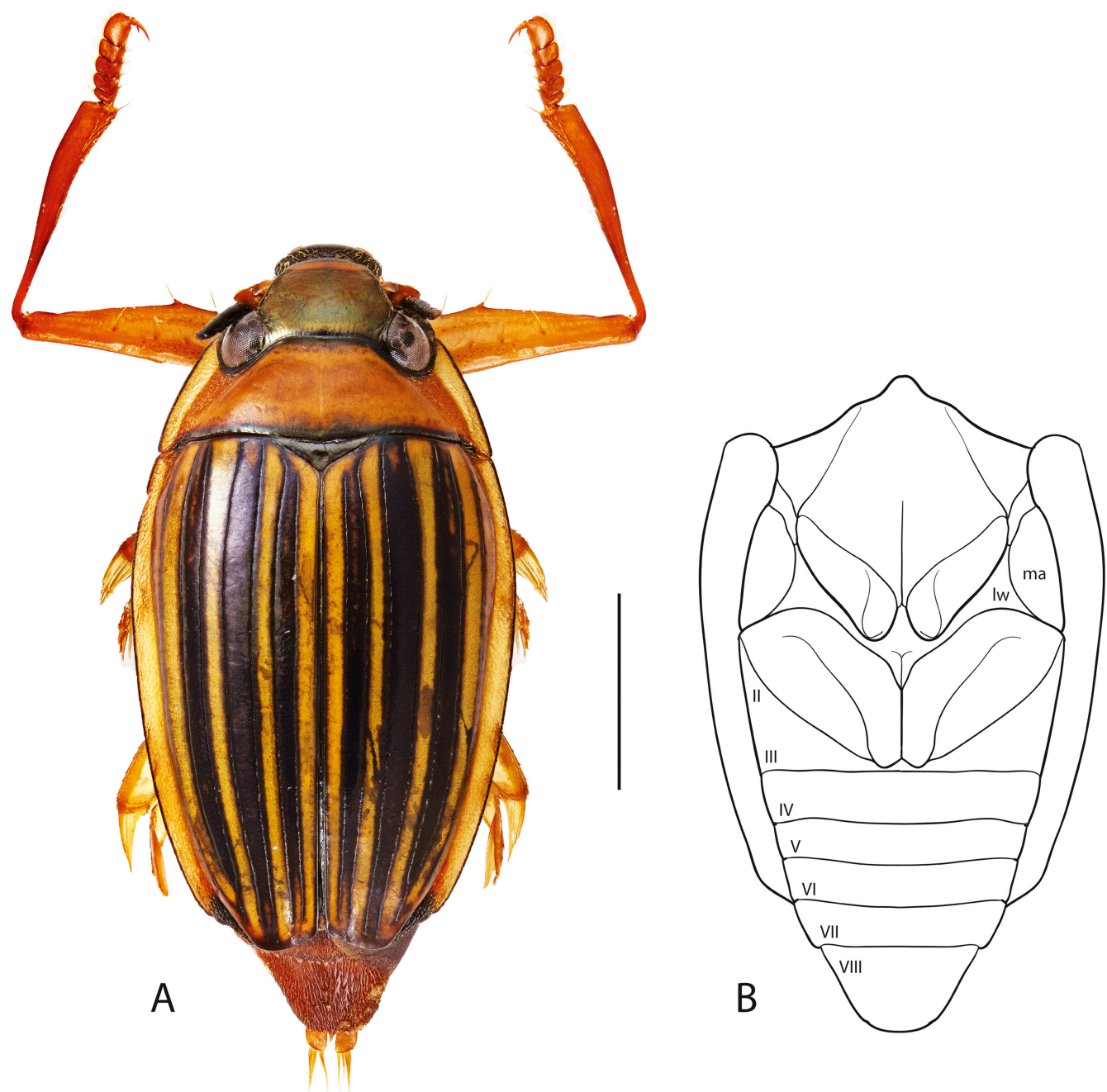

Fig. 1. Heterogyrus milloti. A) Dorsal habitus of male, scale bar $=2 \mathrm{~mm}$, B) Ventral habitus, $1 \mathrm{w}=1$ lateral wing of metaventrite, $\mathrm{ma}=$ metanepisternum, Roman numerals indicate abdominal sternites.

and lowered all the former subfamilies to tribal rank within the nominotypical subfamily Gyrininae, as the species possessed numerous seemingly plesiomorphic conditions relative to all other Gyrinidae. Spanglerogyrus Folkerts was indeed recovered as sister to all other Gyrinidae in the first phylogenetic analysis of the family including molecular data (Miller and Bergsten 2012), supporting its placement in its own subfamily, and the plesiomorphic nature of its morphology. Surprisingly, Miller and Bergsten's (2012) analysis similarly placed Heterogyrus in an isolated position as sister to all the Gyrininae, resulting in elevation of Brinck's (1955) Heterogyrini Brinck to subfamilial status. The study also suggested the morphology of Heterogyrus is transitional between the early diverging Spanglerogyrus and the more derived Gyrininae, supporting its position in the phylogeny (Miller and Bergsten 2012). Miller and Bergsten (2012) were also the first to report briefly on the unusual habitat of Heterogyrus relative to that of other Gyrinidae.

While collecting $H$. milloti during a 2014 expedition to Madagascar, it was observed that live specimens jumped about in the aquatic net after being removed from water. Furthermore, specimens placed in white plastic pans were noted to jump adeptly. To observe the species' behavior in a more natural setting, specimens were placed on a dried stream bed and again found to jump, but in this situation, individuals performed targeted, seemingly non-random hops in a downstream direction. Thus, the authors performed a small behavioral 
experiment to test the hypothesis that $H$. milloti hops in a non-random, targeted downstream manner.

In this paper, we provide a redescription of the species, more information on the habitat of $H$. milloti, report undocumented behavior with results from a small behavioral experiment, and finally discuss the plesiomorphic, transitional, shared, and unique morphology of this species in relation to other Gyrinidae. Finally, common names are proposed for $H$. milloti to aid in communication and conservation of this species.

\section{Material and Methods}

Morphology and Taxonomy. In total, 71 specimens were examined for this study. Material was examined from the following collections:

GTGC Grey Gustafson research collection, currently at Department of Ecology and Evolutionary Biology, University of Kansas, Lawrence, Kansas, U.S.A.

MSBA Museum of Southwestern Biology, Division of Arthropods, University of New Mexico, Albuquerque, New Mexico, U.S.A (K. Miller).

NHRS Swedish Museum of Natural History, Stockholm, Sweden (J. Bergsten).

DEUA Departement d'Entomologie, Université d'Antananarivo, Antananarivo, Madagascar.

For descriptive and comparative purposes, specimens were examined using a Zeiss Discovery. V8 SteREO microscope with attached drawing tube. Illustrations were first prepared under the drawing tube then scanned and traced using the software Adobe Illustrator. Female genitalia were prepared following the methods outlined in Miller and Bergsten (2012) and were illustrated in water. Smaller anatomical structures such as the metacoxa and genitalia were first cleared using $\mathrm{KOH}$ then examined using a Zeiss AXIO Imager A2 compound microscope with attached Axiocam 506 mono camera.

Habitus and other color images were taken on a Visionary Digital BK + light imaging system (www. visionarydigital.com, R. Larimer). Habitus images were edited using Adobe Photoshop CS5 to improve clarity and color and to add scale bars. Scanning electron microscope images were taken at the KU Microscopy and Analytical Imaging Laboratory, University of Kansas, Lawrence, KS, USA.

Behavioral Experiments. Specimens of $H$. milloti were collected from a medium-sized pool in a small stream bed located $-21.24980^{\circ} \mathrm{S}$, $47.40410^{\circ} \mathrm{E}$, at $1,080 \mathrm{~m}$ elevation, in Ranomafana National Park, Fianarantsoa Province, Madagascar on 2 November 2014. Numerous specimens were collected at random using a large strainer, then placed in a water-filled plastic container for holding during experimentation. Water for the holding container was collected from the same pool prior to collecting the beetles. Each trial consisted of first scooping a specimen from the plastic container using a small tea-strainer, placing the specimen on the dried stream bed adjacent to the stream, then observing the specimen's behavior. Each trial $(n=$ 17) was recorded in situ by a Canon Legria HFS 100 camcorder.

For each trial, the specimen was placed roughly in the center of a small $(\mathrm{ca} .30 \mathrm{~cm})$, circular arena of dried stream bed. Once in the arena, specimens were not manipulated and were allowed to acclimate before jumping. Specimens that did not exhibit any movement after $\mathrm{ca}$. 20 seconds were not included in the final sample. Specimens where allowed to jump unimpeded until exiting the arena, at which point they were caught by the first author and removed from the arena. To insure the same specimens were not re-sampled, they were collected into ethanol at the end of each trial. Specimens whose movements were not tracked by the observers present at the time of the trial were also excluded from the final sample. These qualifications resulted in two of the trials being excluded and a final sample size of 15 trials.

\section{Results}

\section{Morphology and Taxonomy}

\section{Heterogyrus milloti Legros, 1953}

Material Examined. MADAGASCAR: Fianarantsoa Province: $7 \mathrm{~km}$ W Ranomafana, 1,100 m, 8-21.x.1988, leg. W. E. Steiner (3 ex. MSBA); same as previous except 1,000 m, 1-7. iii.1990 (3 ex. MSBA); $~ 8 \mathrm{~km} \mathrm{~W} \mathrm{Ranomafana}$ town, stream, 21⒕992'S, 47²4.332'E, 20. xi.2008, leg. K. B. Miller, KBM20110801 (18 ex. MSBA); Ranomafana NP, $3.8 \mathrm{~km}$ SE of Vohiparara village, $21.2498^{\circ} \mathrm{S}, 47.4041^{\circ} \mathrm{E}, 1,080 \mathrm{~m}, 2 . x i .2014$, forest stream by road, leg. G. Gustafson GTG110214D (6 ex. GTGC). Ranomafana NP, $3.8 \mathrm{~km}$ SE of Vohiparara village, $21.2498^{\circ} \mathrm{S}, 47.4041^{\circ} \mathrm{E}, 1,080 \mathrm{~m}$, 2.xi.2014, forest stream by road, Leg. J. Bergsten, T. Ranarilalatiana \& S. Holmgren, MAD14-08, NHRSJLKB000027148 (3 ex. NHRS); Ranomafana NP, $3.8 \mathrm{~km} \mathrm{SE}$ of Vohiparara village, $21.2498^{\circ} \mathrm{S}$, $47.4041^{\circ} \mathrm{E}, 1,080 \mathrm{~m}, 1 . x i .2011$, small forest stream with pools, leg. J. Bergsten, R. Bukontaite, T. Ranarilalatiana \& J. H. Randriamihaja, MAD11-11, NHRS-JLKB000027145 (20 ex. NHRS, 4 ex. DEUA); Ranomafana NP, $500 \mathrm{~m}$ from Micet station by the road, $21.2552^{\circ} \mathrm{S}, 47.41214^{\circ} \mathrm{E}, 960 \mathrm{~m}, 30$. x.2011, small forest stream with sidepools, leg. J. Bergsten, R. Bukontaite, T. Ranarilalatiana \& J. H. 
Randriamihaja, MAD11-01, NHRS-JLKB000027144 (8 ex. NHRS); Ihorombe, R. S. Pic d'Ivohibe corridor: Ampanasaha: at the east limit of the corridor, close to Ampanasaha river: $22.47185^{\circ} \mathrm{S}, 46.957783^{\circ} \mathrm{E}, 926 \mathrm{~m}$, 9.xii.2013, weakly trickling forest stream with dead leaves, MAD13-52, leg. J. H. Randriamihaja \& T. Ranarilalatiana NHRS-JLKB000027147 (1 ex. NHRS); Ihorombe, R. S. Pic d'Ivohibe: Ampanasaha: stream before river Ampanasaha: $22.475516^{\circ} \mathrm{S}, 46.95273^{\circ} \mathrm{E}$, $1,006 \mathrm{~m}$, 8.xii.2013, small stream with pools on rocks, MAD13-50, leg. J. H. Randriamihaja \& T. Ranarilalatiana NHRS-JLKB000027146 (5 ex. NHRS).

Type Locality. Ampasy, upper Iantara valley, southeast of Andringitra massif, Fianarantsoa, Madagascar (Viette 1991). This is located in or just outside the southeastern corner of Andringitra National Park (approximate coordinates $22.3^{\circ} \mathrm{S}$, $\left.47.02^{\circ} \mathrm{E}\right)$.

Diagnosis. Heterogyrus milloti is recognized by the following unique combination of character states: Antennal flagellum 9-segmented, strongly setose with long setae present along anteromedial face of flagellomeres II-IX; eyes widely separated dorsoventrally by well-developed interorbital region, interorbital region with antennal groove; labrum transversely divided by strong infolding with setose anterior margin; maxillary galea 2-segmented; mentum trilobate; prementum not fused to mentum; pronotum with median lobe projecting onto head capsule; lateral margins of pronotum and elytra broad, explanate, setose; scutellar shield visible with elytra closed; elytron with sutural border and nine serial striae, yellow and black striped in coloration; protibial medial spur present; metaventrite with triangular lateral wings, metaventral discrimen with short transverse suture; metacoxae oblique; abdominal sternite VIII trilobate in males, bifid in females.

Redescription. Size: ${ }^{t}$ length $6.0-6.5 \mathrm{~mm}$, width $3.0-3.5 \mathrm{~mm}$; ㅇ length $5.7-6.0 \mathrm{~mm}$, width $3 \mathrm{~mm}$. Habitus: Medium size; body elongate oval, weakly attenuated posteriorly; in lateral view, strongly dorsoventrally depressed, slightly humped posteriad to scutellar region. Coloration: Head with vertex bronzy green medially, posteriorly near pronotum and ocular region black; frons laterally bronzy green, becoming more golden bronzed medially, frontolateral margins black; clypeus yellow; labrum dorsally black, yellow beneath fringe of setae; antennal scape, pedicel, and first flagellomere yellow, remaining flagellomeres black; pronotum medially golden yellow, posterior margin black, pale yellow lateral margins with black border; elytral suture and striae lined in black, black stripes present on intervals II, IV, VI, and VIII at least posteriorly, remainder of elytra yellow, elytral lateral margin pale yellow with black border, elytral apex including margin black; scutellar shield anteromedially reddish orange, black laterally and apically; protarsal claws red; venter overall light yellowish orange, propleuron and epipleuron paler yellow in color, ventral eye ocular region black, abdominal tergites brownish orange. Head: Vertex with well impressed reticulation composed of round, irregular sculpticells, sparse, weakly impressed, nearly imperceptible punctation present; dorsal eye with thick, raised margin, eyes widely dorsoventrally separated with well-developed interorbital region; interorbital region with antennal groove, setae present medially dorsad and ventrad to groove; frons with similar reticulation and punctation as vertex, frontolateral margin with welldeveloped bead (Fig. 2A, B), lightly wrinkled; frontoclypeal suture well developed, crescentshaped; clypeus with lightly impressed reticulation composed of polygonal sculpticells, weak punctation present, most evident at anterior margin, punctures separated by $c a$. 2-3X diameter of single puncture; clypealia elongate, extending well onto posterolateral corners of labrum, setose; antennal scape cup-shaped; pedicel triangular in shape; flagellum with 9 flagellomeres (Fig. 3A), flagellomeres II-IX with long, yellow setae on anterior face, V-IX setose with smaller, finer setae, ultimate flagellomere nearly entirely covered with setae (Fig. 3B); labrum strongly transverse, basally divided by strong, transverse infolding (Fig. 1A), fold lined with long, gold setae, dorsad of fold reticulation composed of round, polygonal sculpticells, posteriorly with long, yellow setae present in recessed punctures, ventrad of fold without reticulation or punctation, ventral margin of labrum lined with setae; maxilla with 2-segmented galea; lacinia narrow and arcuate in form, with 2 patches of setae present on medial surface; maxillary palp 4-segmented with ultimate segment $c a$. $3 \mathrm{X}$ length of penultimate; labial palp elongate and narrow, 3-segmented with ultimate and penultimate palpomeres similar in length, both at least 2X length of segment I, apical palpomere weakly curved; palpigers fused medially, prementum distinctly separated from mentum by membranous area (Fig. 2C, D); mentum trilobate with lateral lobes $2 \mathrm{X}$ length of medial lobe, medial lobe margined anteriorly (Fig. 2D); gula broad and trapezoidal, gular suture present and well developed, reaching anterior margin, narrow sulcus present medially. Thorax: Pronotum with strong medial lobe extended onto head capsule as far as posterior $1 / 3$ of dorsal eye (Fig. 2B), medially weakly sinuate; pronotal disc with reticulation composed of polygonal sculpticells, with weakly impressed punctation separated by $0.67 \mathrm{X}$ diameter of single puncture; transversly impressed pronotal line briefly evident laterally before joining anterior border (Fig. 2B); pronotal setose border present laterally (Fig. 2B), width $0.67 \mathrm{X}$ diameter of dorsal eye anteriorly, attenuated posteriorly; pronotal lateral margin broad, explanate, setose; prosternum 

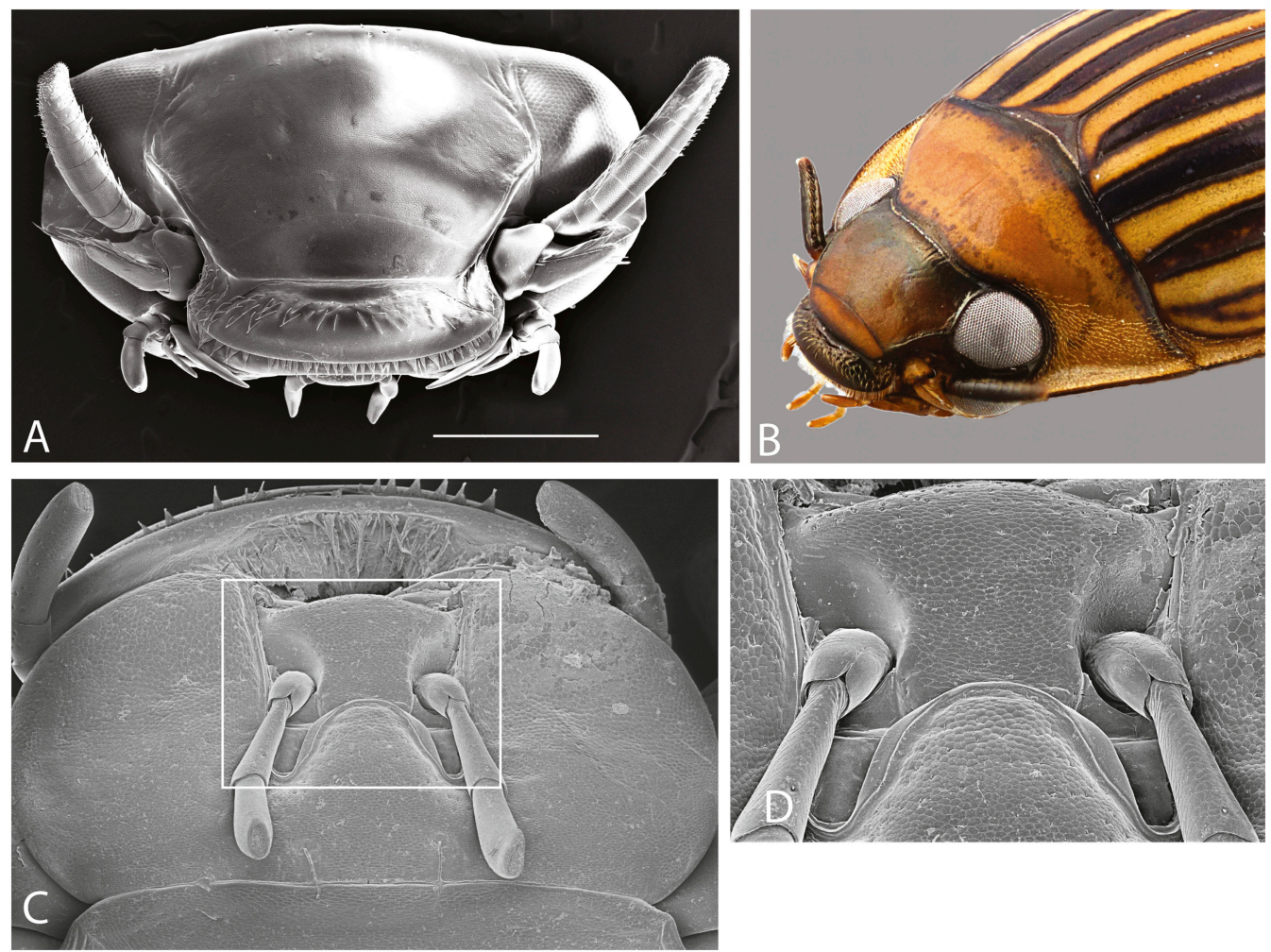

Fig. 2. Heterogyrus milloti. A) Head capsule anterior view, scale bar $=500 \mu \mathrm{m}, \mathrm{B}$ ) Oblique view of anterior half of body, C) Mentum and prementum, box indicates area shown in D, D) Prementum and medial lobe of mentum.

cushion-shaped with medial shallow depression (Fig. 4); notopleural and propleurosternal sutures present, meeting anteriad at anterior border of pronotum, forming very short notosternal suture; propleuron with shallow depression for leg reception; forelegs with protrochanter glabrous; profemur strongly swollen basally, male profemur basally with 2-3 distinct denticles present; basal half of profemur with series of long, fine setae along posterior margin of ventral face; ventral face of profemur apically with depression for reception of protibia; anterior face of profemur with 4 setigerous punctures, short stout setae in recessed pits also present basoposteriorly; protibia narrow, sinuate; apical 1/2 of ventral face setose, setation primarily composed of narrow, yellow setae, longer setae $3 \mathrm{X}$ length of shorter abundant setae fairly evenly spaced along setose region, apical margin of ventral protibial face ringed with stout setae; posterior face of protibia with additional line of short, yellow setae, reduced protibial brush present; medial protibial spur present (Fig. 5C, stb); apicolateral corner of protibial apex with few peg-like setae (Fig. 5c, lps); protarsus of male with posterior surface covered with narrow, elongate, adhesive setae of uniform type, adhesive setae fused into 5 plates (Fig.
5A); lateral and posterior margins of adhesive palette with fringe of long, fine, yellow setae; posterior face of female protarsus covered in yellow setae, anterior face of protarsus of both sexes with protarsomeres I-IV possessing setose patches at distomedial corner; protarsomere $\mathrm{V}$ at least $2 \mathrm{X}$ size of $\mathrm{IV}$, with small setose patch distomedially; protarsal claws emerging straight in female, at $90^{\circ}$ angle in male; scutellar shield transverse, short and triangular, visible with elytra closed; elytron with 9 distinct serial striae (Fig. 9G); striae I-VI present as lineate grooves; stria VII composed of faintly impressed punctures; stria VIII present as punctures evident in humeral region, remaining punctures highly reduced, almost imperceptible; stria IX lineate, situated at lateral margin; elytral sutural border present; lateral margin of elytra setose, broad and strongly explanate, ending at elytral apex; mesoventrite triangular and elongate, anteriorly bordered with strong medial projection; mesothoracic discrimen well developed; laterally depressed along with mesanepisternum for foreleg reception, depression running nearly $1 / 2$ mesoventrite length; mesepimeron narrow and strap-like; middle legs with elongate triangular mesocoxa running obliquely, mesocoxal process with paramedial setose patch 

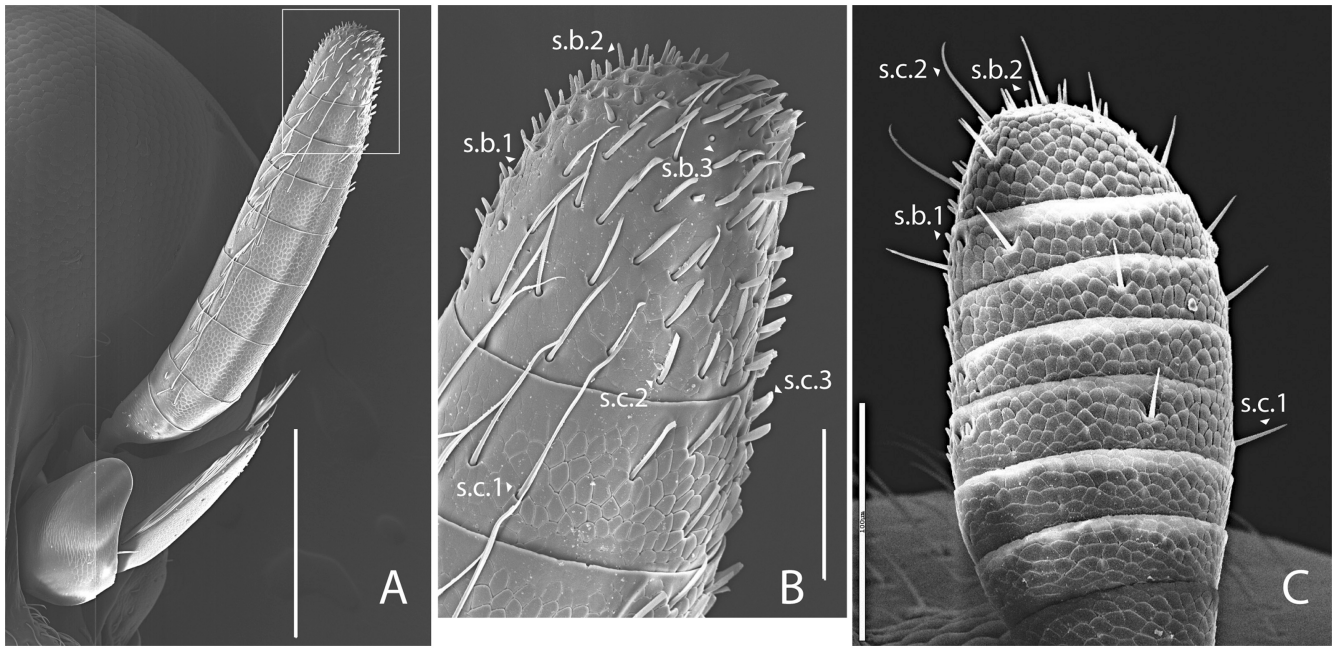

Fig. 3. Antennae of Heterogyrus milloti and Spanglerogyrus albiventris. A) Antenna of H. milloti, box indicates area shown in $\mathrm{B}$, scale bar $=300 \mu \mathrm{m}$, B) Antennal apex of $H$. milloti, s.b. = sensilla basiconicum type, s.c. $=$ sensilla chaetica type, scale bar $=50 \mu \mathrm{m}, \mathrm{C}$ ) Most of antennal flagellum of $S$. albiventris, scale bar $=100 \mu \mathrm{m}$.

basally; mesotrochanter short and trapezoidal; mesofemur broad, dorsal margin distally with sparse, long setae; mesotibia broad with distal lateral angle produced, margin with evenly spaced peg-like setae, dorsal margin of posterior face with long natatory setae, distal ventral corner of mesotibia with short series of peg-like setae; 2 mesotibial spurs present, posterior spur over twice as long as anterior spur; mesotarsus elongate, narrow; mesotarsomere $I$ in form of isosceles triangle, proximal dorsal lobe possessing small fringe of natatory setae; II-IV narrow, trapezoidal; $\mathrm{V}$ quadrate, dorsally with fringe of natatory setae; all mesotarsomeres ventrodistally with stout spine-like setae; mesotarsal claws small, not sexually dimorphic; metaventrite medially narrow (Fig. 1B), diamond-shaped, metaventral discrimen present with short transverse sulcus anteriorly (Fig. 9F), lateral wings of metaventrite in form of nearly equilateral triangle, metanepisternum lobiform; hind leg with metacoxae running obliquely (Fig. 1B); metacoxal process with shallow punctures, very weakly impressed transverse reticulation, setose patches present paramedially; in lateral view, metacoxal cavity narrowed anteriorly, ventral margin with distinct peg posteriorly (Fig. 11B); remainder of hind leg similar in form to middle leg. Abdomen: Dorsally abdominal tergites VI-VIII pigmented and setose, VII and VIII densely covered with long setae; abdominal sternites II + III (ventrite I) $2 \mathrm{X}$ size of sternite IV, sternites IV-VII similar in size and form, sternite VIII (ventrite VI) triangular, bifid apically in females, trilobate in males (Fig. 6A, B). Genitalia: Aedeagus with median lobe slightly shorter than parameres, evenly narrowed towards apex, with distinct subapical lateral expansion (Fig. 7); in dorsal view, expansion with arcuate grooves (Fig. 7A); apex acuminate, flatly rounded; in doesal view, median lobe with 2 paramedial grooves; 1 medial longitudinal list evident; in ventral view, sperm groove narrow, mostly parallel-sided, weakly expanded proximally (Fig. 7C); in lateral view, apex dorsally curved (Fig. 7B); parameres in dorsal view weakly laterally expanded in apical $1 / 3$, apex obliquely truncate with lateral angle distinct, long setae confined to apex, medially weakly reflexed; in ventral view, basal piece present as distinct sclerite, fused to parameres (Figs. 7C, 9C, D), basally with acuminate process directed anteriorly. Female reproductive tract (Fig. 8) with ovoid spermatheca atop 2 strongly sclerotized vshaped ridges; sclerotized v-shaped ridges potentially associated with fertilization duct (Fig. 8A);

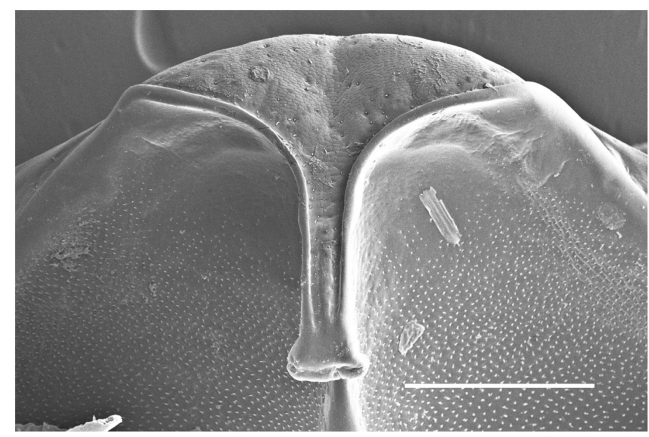

Fig. 4. Prosternum of Heterogyrus milloti, ventral view, scale bar $=200 \mu \mathrm{m}$. 

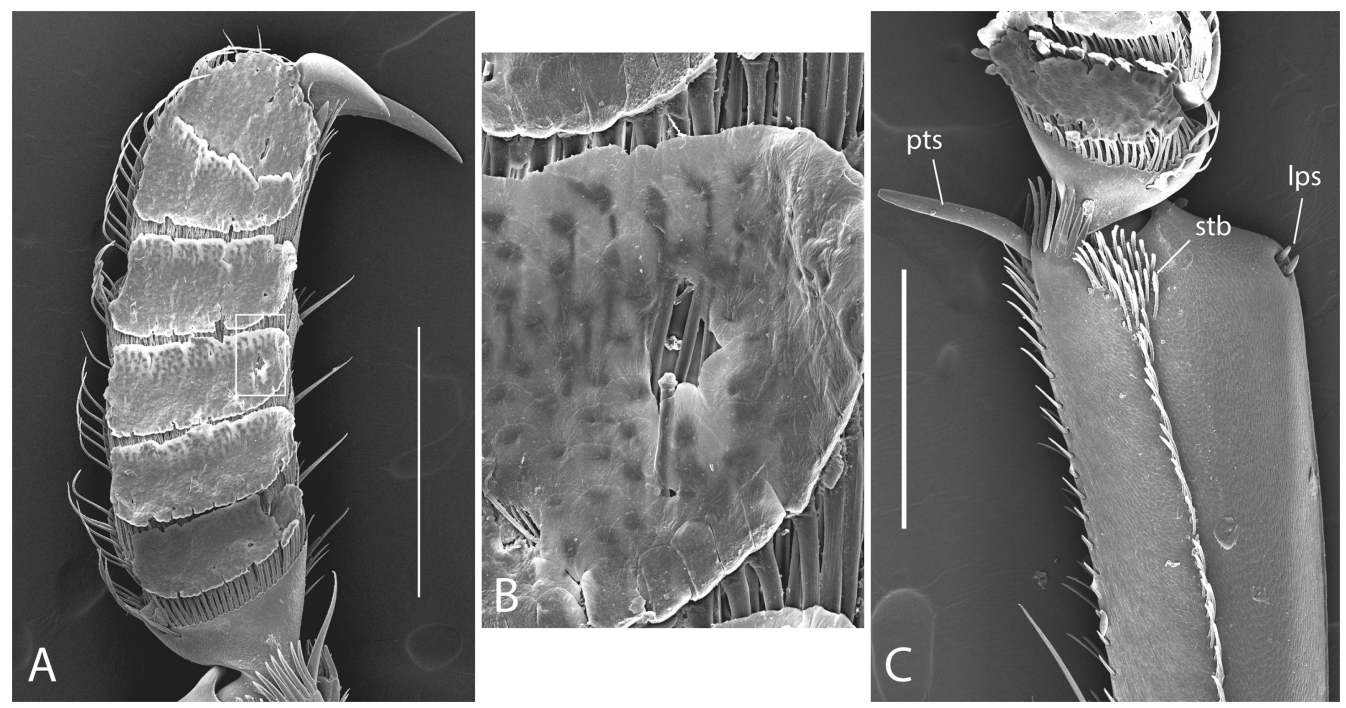

Fig. 5. Heterogyrus milloti. A) Male protarsus, posterior view, box indicates area shown in B, scale bar = $400 \mu \mathrm{m}, \mathrm{B})$ Adhesive setae, showing fusion of individual adhesive setae into plate, C) Protibial apex, lps = peg-like lateral setae, $\mathrm{pts}=$ protibial medial spur, $\mathrm{stb}=$ setose brush, scale bar $=300 \mu \mathrm{m}$.

spermatheca subapically with elongate spermathecal duct emergent dorsally, basally with sac-like spermathecal gland also emergent dorsally anteriad to strongly sclerotized dorsal fold (Fig. 8B); gonocoxae stout, rectangular, setose (Fig. 8A); medial apodeme present; lateral tergites relatively broad, weakly expanded apically.

Sexual Dimorphism. There is sexual size dimorphism with males normally larger than females. The profemora are sexually dimorphic in form with males having the profemur more swollen basally and adorned with three distinct denticles. In females, there is slight indication of the denticles at the base of the profemur, but they are clearly reduced, only evident in the distal one, corresponding to the most strongly produced denticle in the male. The ultimate abdominal ventrite is strongly sexually dimorphic. In females, abdominal sternite VIII is apically bifid, whereas in males it is distinctly trilobate (Fig. 6B). The trilobed nature of the male abdominal sternite VIII is proposed to be an intermediate step in a transitional series from the deeply divided abdominal sternite VIII of males of Spanglerogyrus to the undivided sternite VIII of the Gyrininae (see Miller and Bergsten 2012 for more details).

Distribution. This species is known only from a few localities in the mountainous escarpment of southeastern Madagascar, Upper Iantara River valley (southeast of Andringitra massif), Pic d'Ivohibe Special Reserve (S. R.), and Ranomafana National Park (N. P.).

Habitat. The 2014 specimens were collected in a narrow gully within montane rainforest
(Fig. 10 and Movie 1: www.youtube.com/watch? $\mathrm{v}=\mathrm{oQAkdGNwhjQ)}$ ). The gully was choked with debris such as logs, broken branches, and boulders, potentially the result of past flooding. The stream itself was mostly a trickle forming pools and retreating underground at points. Adjacent to the larger pools, the rocks were wet and covered with moss. The larger pools with greater numbers of specimens were often no more than $c a .15 \mathrm{~cm}$ deep with sandy bottoms and leaf packs. Individuals could also be found in the dark recesses under overhangs of rocks and logs. Steiner's labels give a similar description of the habitat, where in 1988 Heterogyrus was collected: "stream with mossy rocks and sandy bottom, montane rainforest." A few specimens were collected in 2011 in a similar forest stream crossing the road about $1.7 \mathrm{~km}$ southeast of the first locality in Ranomafana N. P., right below the road where the stream runs in a culvert. In 2013, a specimen was collected in a somewhat different habitat in Pic d'Ivohibe S. R. This locality consisted of a weakly trickling forest floor stream with leaf-choked pools. A few more specimens were found in another nearby stream with rocks and pools. Both streams were found in near pristine humid forest at a similar altitude to the ones in Ranomafana (900-1,000 m).

\section{Behavioral Experiments}

In 12 of the 15 trials, specimens of $H$. milloti were observed to orient themselves and jump in a downstream direction (Movie 2: www.youtube. 

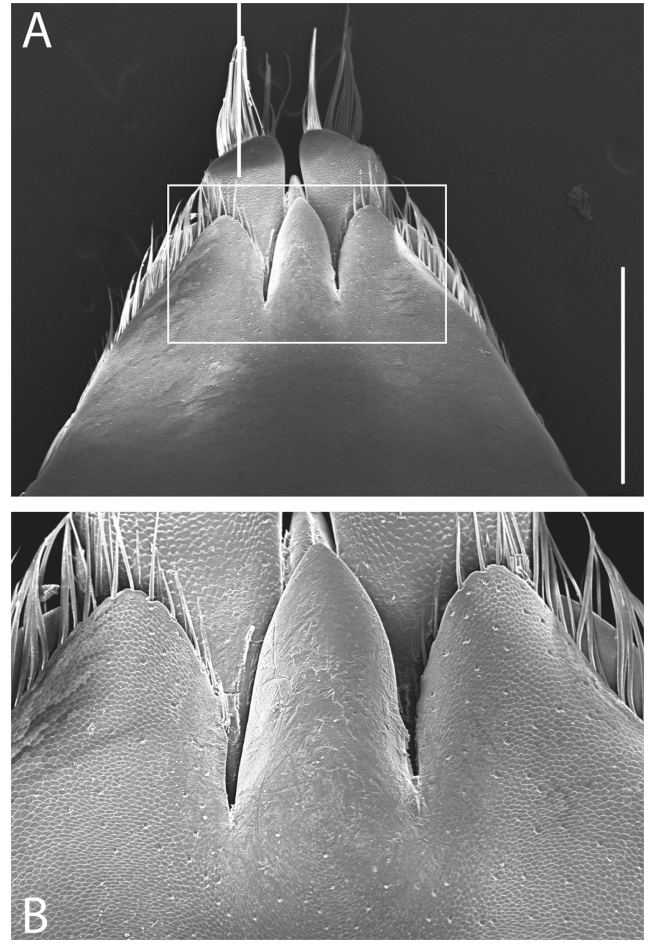

Fig. 6. Heterogyrus milloti. A) Male abdominal sternite VIII, box indicates area shown in B, scale bar $=500 \mu \mathrm{m}, \mathrm{B})$ Apex of male abdominal sternite VIII.

com/watch? $\mathrm{v}=09 \mathrm{PUmU}$-ThO4). Only in three instances did specimens jump in a random, nondownstream direction out of the arena. A Chisquared test (performed in the software R (R Core Team 2016)) significantly rejected the null hypothesis of random jumping $\left(\chi^{2}=5.4, P=0.02\right)$. Thus, indeed $H$. milloti performs targeted jumps, in a downstream direction. In all trials in which specimens moved at all, the beetles moved by saltation. No specimens observed during any trials on the natural substrate attempted to take flight or ambulate away. Furthermore, no specimens of $H$. milloti were observed to fly subsequent to being removed from water, in any situation, while being collected on 2 November 2014.

The slowed video footage of specimens in a white collecting pan (Movie 3: www.youtube.com/watch? $\mathrm{v}=\mathrm{qRqzBVdADd} 4$ ) shows that preceding a jump, H. milloti first raises the anterior half of its body to about a $45^{\circ}$ angle using its long forelegs. This suggests propulsion for the jump likely comes from the rear legs. Following a jump, specimens of $H$. milloti were able to cling to the vertical wall of the pan. From here, specimens were still able to jump despite being positioned on the vertical wall.

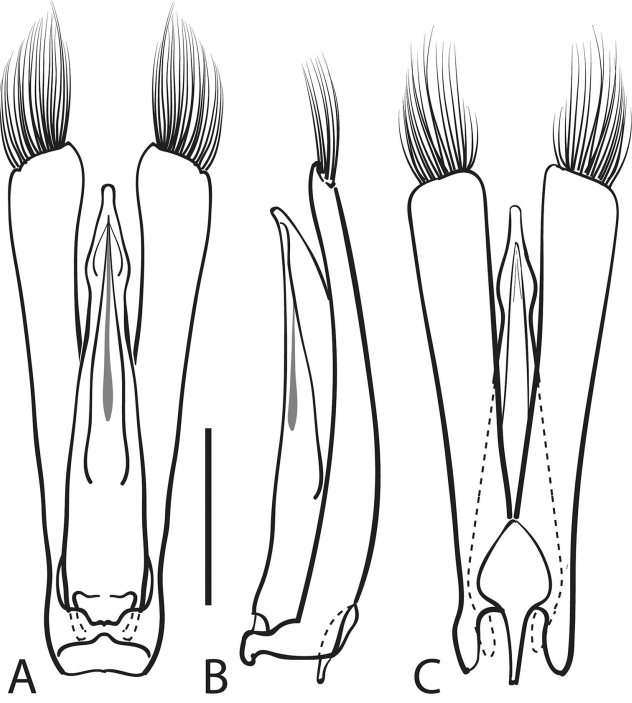

Fig. 7. Heterogyrus milloti, aedeagus. A) Dorsal view, B) Lateral view, C) Ventral view. Scale bar = $1 \mathrm{~mm}$.

\section{Discussion}

Morphological Evidence for the Phylogenetic Placement of Heterogyrus. There are several distinct symplesiomorphic features Heterogyrus shares with Spanglerogyrus, which are lost in most or all other Gyrininae. These are: 1) labrum transversely divided by a line of setae (Fig. 2A); 2) setose antennal flagellum (Fig. 3A); 3) prementum not fused to mentum (Fig. 2D); 4) pronotum with a medial lobe extended well onto the head capsule (Fig. 2B); and 5) protibia with medial spur (Fig. 5C). Of these traits, only the transversely divided labrum is still evident in a few Gyrinini (e.g., Gyrinus minutus Fabricius, 1798). The ultimate antennomere of some Gyrinini also retain some setae, but never developed to the extent in Spanglerogyrus or Heterogyrus. Traits 3 and 5 strongly suggest placement of Heterogyrus outside of the Gyrininae.

Miller and Bergsten (2012) provided some examples of intermediate morphology exhibited by Heterogyrus to support their preferred phylogenetic placement of Heterogyrus as sister to the Gyrininae. These included the short transverse sulcus of the metaventral discrimen (Fig. 9F) and the unique trilobate apex of the male ultimate abdominal ventrite (Fig. 6A, B). We here report on new convincing intermediate morphology, again associated with the male. The aedeagus of Heterogyrus has a distinct sclerite associated with the parameres that we propose to be homologous with the basal piece (Fig. 9C, D). The position of the sclerite is similar to that of the basal piece of Spanglerogyrus (Fig. 9A, 


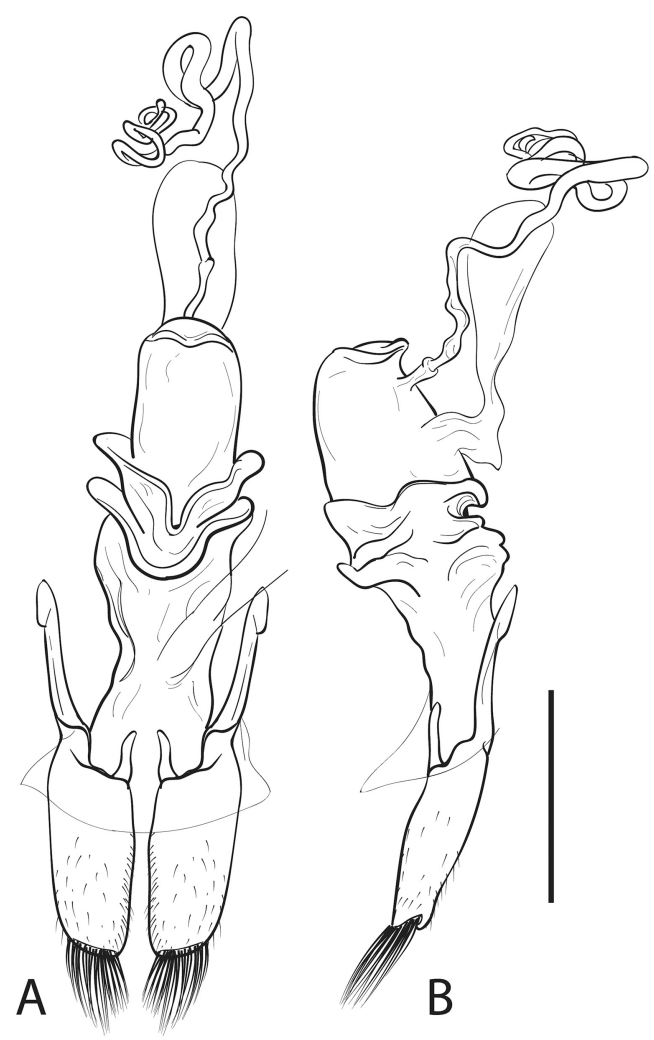

Fig. 8. Heterogyrus milloti, female reproductive tract. A) Ventral view, B) Lateral view. Scale bar = $0.75 \mathrm{~mm}$.

B), and the structure of the sclerite includes a distinct anteriorly projecting process situated basally, similar to the basal acumination of the basal piece of Spanglerogyrus (Fig. 9B). Furthermore, interpreting this sclerite as the basal piece explains the odd anteriorly projecting basoventral process of the parameres of the Gyrinini (Fig. 9E, bvp). This transitional series reveals the fate of the basal piece in the Gyrinidae: it became fused to the parameres in the common ancestor of Heterogyrinae + Gyrininae, becoming indistinct from them in the Gyrinini, and finally totally reduced to absent in the Dineutini and Orectochilini. It should be pointed out that older literature (reviewed by Brinck 1955) previously claimed the aedeagus of members of Gyrininae possesses a large basal piece. Brinck (1955) examined the aedeagal morphology of the Gyrininae to clarify the anatomy and terminology, concluding the basal piece referred to by previous authors actually denotes the modified abdominal sternite IX of males, which forms a sheath surrounding the aedeagus when un-extruded.
The mentum of Heterogyrus (Fig. 2C) also forms a telling transitional series. In Spanglerogyrus, the mentum is composed of large lateral lobes, without a medial projection, and the prementum is distinct from the mentum with palpigers that are unfused medially (Beutel and Roughley 2005). In Heterogyrus, the palpigers have fused medially (Fig. 2D), but the prementum remains unfused to the mentum, as indicated by the presence of a membrane surrounding its base (Fig. 2D). The mentum of Heterogyrus also includes a distinct medial lobe (Fig. 2C) extending anteriorly on to the basomedial portion of the prementum that in the Gyrininae has fused with the prementum to form a solid plate. All together, these transitional series provide strong support for the intermediate phylogenetic position of Heterogyrus, being more derived than Spanglerogyrus in key features, yet less derived than the Gyrininae.

Heterogyrus also has features in common with all three tribes of the Gyrininae, suggesting these two lineages share a more recent common ancestor. Similar to the Orectochilini, Heterogyrus has a cushion-shaped prosternum (Fig. 4), without a raised and well-developed medial process (seen in Gyrinus Geoffroy, 1762 and Dineutus Macleay, 1825), as pointed out by Brinck (1955). Brinck (1955) also suggested the male protarsi of Heterogyrus are similar in form to the orectochilines. Like the Gyrinini, the metacoxae of Heterogyrus run obliquely (Fig. 1B), and the aedeagus still retains evidence of the basal piece (Fig. 9C, E). Heterogyrus shares the most traits with the Dineutini, having triangular lateral wings of the metaventrite and nine elytral striae (as indicated by Brinck 1955), but also a lobiform metanepisternum (Fig. 1B).

The Unique Behavior, Morphology, and Habitat of Heterogyrus. Saltation has been observed before in few other groups of aquatic beetles. Jumping is also known from members of the dytiscid subfamily Laccophilinae and the genus Hydrotrupes Sharp (Miller and Bergsten 2016). It has also been noted in two other whirligig beetle genera, Gyretes Brullé, 1835 and most interestingly Spanglerogyrus (Folkerts 1979; Steiner and Anderson 1981). The jumping of Gyretes is 'shrimp-like', being accomplished via ventral contraction of the abdomen, using the last three abdominal segments as a lever (Walls 1974; G. Gustafson, personal observation). The manner in which Spanglerogyrus jumps is unknown as their exceptionally small size ( $c a$. $3 \mathrm{~mm}$ ) makes observation extremely difficult.

The slowed video footage of Heterogyrus suggests jumping is generated by the rear legs (see Results section). While the exact mechanism behind the jumping was not specifically tested, an investigation of the morphology of the metacoxae revealed a peculiarity potentially associated with 

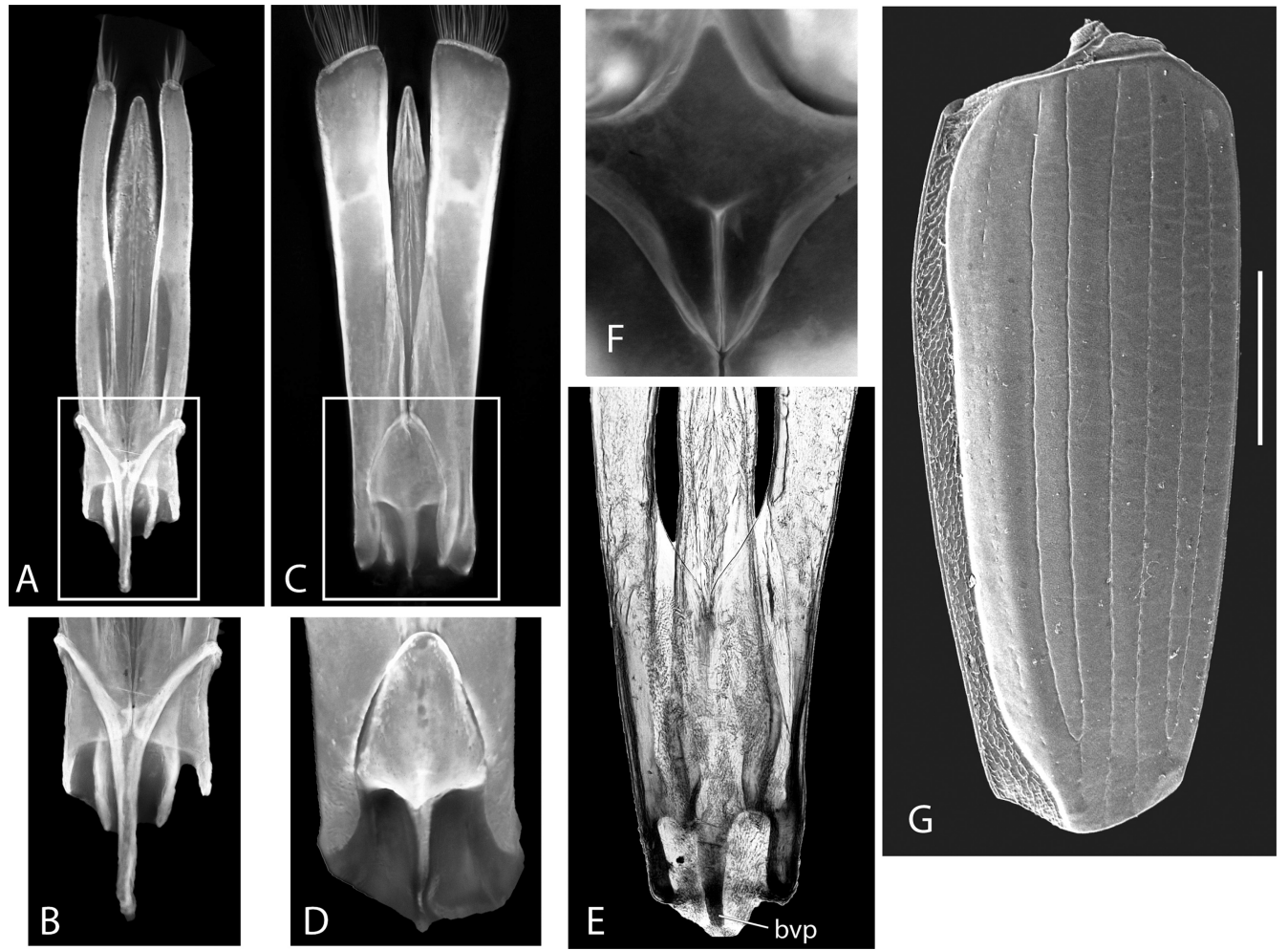

Fig. 9. Morphology of Heterogyrus milloti, Spanglerogyrus albiventris, and Gyrinus amazonicus Ochs. A) Aedeagus of $S$. albiventris, ventral view, box indicates area shown in B, B) Basal piece of $S$. albiventris, C) Aedeagus of $H$. milloti, ventral view, box indicates area shown in D, D) Basal piece of $H$. milloti, E) Most of aedeagus of $G$. amazonicus, ventral view, bvp = basoventral process, F) metaventrite of $H$. milloti, showing metaventral discrimen with short transverse sulcus, G) Left elytron of $H$. milloti, scale bar $=1 \mathrm{~mm}$.

jumping behavior. The metacoxal cavity of Heterogyrus is considerably narrowed anteriorly and possesses a distinct peg-like structure (Fig. 11B) on its ventral margin, basal to this narrowing. These features are absent in the mextacoxal cavities of Spanglerogyrus (Fig. 11A), Gyrinus (Fig. 11C), and Gyretes (Fig. 11D) as well as the mesocoxa of $H$. milloti. Importantly, these metacoxal cavity features are found in both sexes of $H$. milloti. The anteriorly narrowed cavity and basal peg of the metacoxa may serve as a friction hold for the metafemur to allow $H$. milloti to jump more powerfully. The jump of click beetles (Elateridae) is accomplished with an analogous peg and friction hold mechanism (Evans 1972). The jumping mechanism of $H$. milloti appears most similar to that of laccophiline dytiscids, which similarly have the peg for the friction hold situated on their metacoxae (Miller and Bergsten 2016).

The behavioral experiment revealed that jumps by $H$. milloti are targeted in a downstream direction. How detection of the downstream direction is accomplished is unknown, but could potentially be associated with the detection of abundance of water. The antennae of $H$. milloti are very strongly setose, with many types of sensilla evident in the antennal apex (Fig. 3B), including three types of sensilla chaetica and three types of sensilla basiconicum (Merivee et al. 2000, 2001). Of these setae, the sensilla chaetica type 3 (Fig. 3B, s.c.3) is particularly interesting as it is uniquely shaped compared to the sensilla known from other adephagans (Merivee et al. 2000, 2001), being short and spatulate. Furthermore, the presence of these sensilla on the antennae of $H$. milloti cannot be explained by common ancestry with Spanglerogyrus alone, as the sensilla of H. milloti (Fig. 3B) are considerably more diverse and of different form than those found in $S$. albiventris (Fig. 3C). Given a variety of antennal sensilla serve as hygroreceptors in beetles (Altner and Loftus 1985), including other adephagans (Merivee et al. 2010), the increased sensilla on the antennae of H. milloti may be associated with improved hygroreception and detection of the downstream direction. 

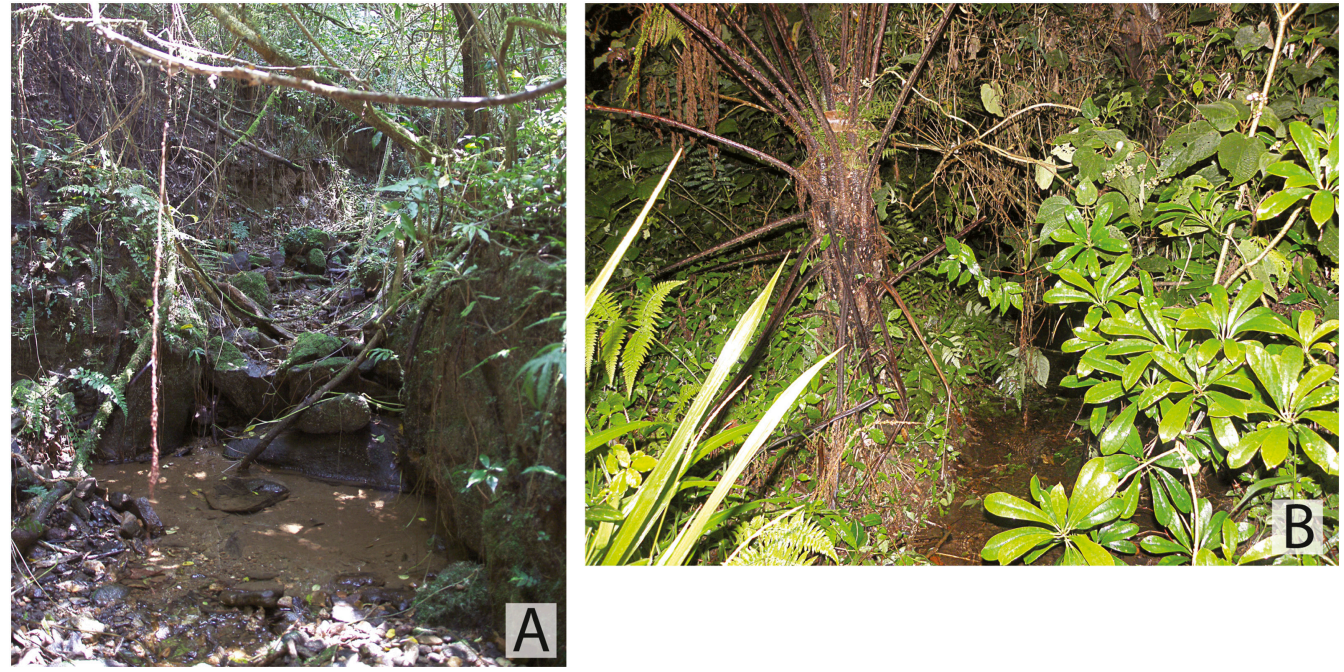

Fig. 10. Habitat of Heterogyrus milloti. A) Forest stream $3.8 \mathrm{~km}$ SE of Vohiparara village, $21.2498^{\circ} \mathrm{S}$, $47.4041^{\circ} \mathrm{E}, 1,080 \mathrm{~m}$, Ranomafana National Park, Fianarantsoa, Madagascar, B) Forest stream approximately $8 \mathrm{~km} \mathrm{E}$ of Ivohibe village, $22.4755^{\circ} \mathrm{S}, 46.953^{\circ} \mathrm{E}, 1,010 \mathrm{~m}$, Ampanasaha, Pic d'Ivohibe Special Reserve, Ihorombe, South of Andringitra N.P. Fianarantsoa, Madagascar.

Males of $H$. milloti have the protarsus modified with a very unusual setose palette configuration where the individual adhesive suction cup setae are fused together into five distinct plates (Fig. 5A, B). The function of this modification is unclear. In other adephagan water beetles, particularly the dytiscines, the adhesive setae have changed shape and size in response to modification of the female elytron, as part of a sexually selected 'arms race' (Miller 2003; Bergsten and Miller 2007). Modification to the size and shape of adhesive setae has been shown to alter adhesive capabilities (Chen et al. 2014). Females of $H$. milloti, however, do not exhibit sexually dimorphic elytra like the dytiscines (Miller 2003; Bergsten and Miller 2007), thus modification of the male protarsal palette does not seem likely to be in response to the female elytron. The video of $H$. milloti jumping showed that specimens were able to adhere to a vertical wall of a plastic container. This modification may affect the adhesive abilities and the observed behavior, but also the sexually selected adhesive setae in dytiscines can be used for climbing, for example, on the glass of an aquarium (J. Bergsten, personal observation).

The habitat of $H$. milloti is quite unusual for a whirligig beetle, and no other gyrinids were
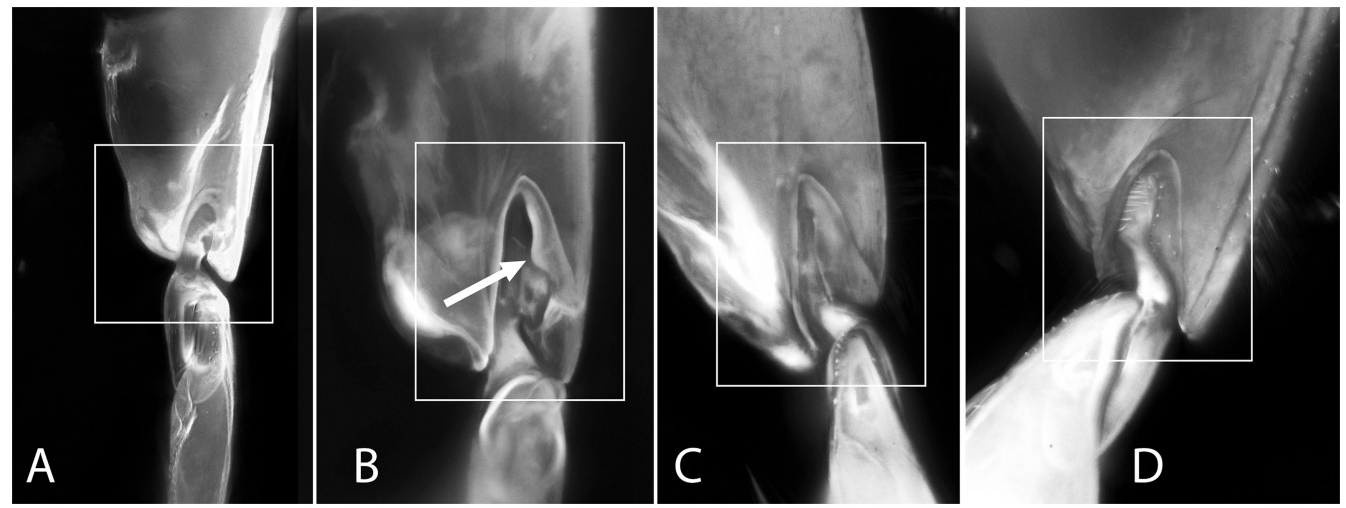

Fig. 11. Metacoxae of Gyrinidae, right lateral view showing metacoxal cavity, boxes indicate focal areas. A) Spanglerogyrus albiventris, B) Heterogyrus milloti, arrow indicates peg, C) Gyrinus sp., D) Gyretes sp. 
observed to co-exist with $H$. milloti despite many species found in a variety of habitats in the surrounding area, both at higher and lower elevations, during the 2014 expedition. The unique jumping behavior and morphology of $H$. milloti may well be adaptations to such a unique habitat. Given the small trickling nature of the streams in which $H$. milloti is collected, many of the smaller pools are likely to become dry over the dry season. Under such a scenario, $H$. milloti must frequently travel to other pools of water. Based on our observations, jumping appears to be the preferred form of locomotion when removed from water. This may be more energy efficient than flight and an easier way to move, given these gully habitats are often tangled with debris and overgrown in areas with vegetation. Jumping downstream is likely advantageous for locating larger pools of water within a trickling stream, explaining the directed nature of the jumping. Detecting larger deposits of water in these small stream habitats may have resulted in selection for the diverse sensilla exhibited on the antennae of H. milloti, allowing for improved hygroreception and the downstream movement behavior. The adhesive setae of the male protarsus being fused into pads may be an adaptation for improved adherence to slick surfaces, like the wet rocks and logs surrounding the larger pools that $H$. milloti frequents, improving the ability to jump in these areas. One may expect if the selective pressure for adhering to slick surfaces is great enough to result in adaptive protarsal setal pads in males, there should also be an analogous adaption in the female protarsus. While this does not appear to be the case, it could merely be the result of constraints on the adaptability of the female protarsus, with the male adhesive setae being readily exaptable. The plasticity of male protarsal adhesive setae in aquatic adephagans is quite evident given their diversity of form and distribution patterns (Miller 2003), as is the adaptability of such modifications (Chen et al. 2014) in support of this scenario.

Conclusions. Heterogyrus milloti is an exceptionally unique gyrinid taxon, preserving intermediate morphology forming several convincing transitional series between the plesiomorphic features of Spanglerogyrus and the derived condition in the Gyrininae. Heterogyrus has been rarely collected and is known only from a few localities within a narrow region of one of the most threatened biodiversity hotspots on the planet (Myers 2000; Mittermeier et al. 2011). The loss of this monotypic genus would mean losing a critical link for studying the evolution of the Gyrinidae. Furthermore, the unique habitat and its potential relation to the peculiar behavior and morphology of H. milloti is unlike that of any other gyrinid and worthy of further investigations. The complete life history of
H. milloti remains unknown, but is of exceptional interest, given the above considerations. These prospective future studies will be rendered impossible if we lose this taxon to extinction.

Known localities of H. milloti in Ranomafana N. P. are not under any current threat as this is one of the flagship national parks of Madagascar and one of the most visited by tourists. It was formed in 1991 following the discovery of the golden bamboo lemur (Hapalemur aureus Meier, Albignac, Peyriéras, Rumpler, and Wright, 1987). However, the accessibility makes non-authorized collecting a potential threat.

The localities in Pic d'Ivohibe S. R. were also found in intact near pristine forest. This special reserve was established in 1964 and is an extended part of the Andringitra massif. The reserve is managed through collaboration between Madagascar National Parks, local people, and other partners. There were no disturbance signs in 2013, except at the entrance and the west edge of the reserve. A trail used by locals runs through the forest, who sometimes take zebu cattle with them. This could affect nutrient levels in the streams, but there were no serious signs of this.

The situation was quite different when visiting Andringitra National Park in November 2013. The type locality of $H$. milloti is not exact and may be located inside or just outside the park's southeastern limit where the Iantara River runs. Only about 30\% of the park is covered by forests, and this is divided into three forest ecozones: mid-altitude rainforest (east part); montane highland forest; and high altitude vegetation in the west. However, these forested areas of the park are threatened by human activities. Much of the humid lowland forests surrounding the park have been cleared for farming methods, such as rice paddy cultivation and slashand-burn agriculture. During our visit in 2013 to the northern part of the park, there were signs of fire around camps 2 and 3 . In addition, particularly at circuit Imaitso (located at, and part of, the eastern mid-altitude humid forest), local people also use the forest as a refuge for their zebu cattle, for fear of zebu robbers. We noticed many tracks and zebu defecation during our visit. This situation results in high levels of disturbance and increased nutrient load to the aquatic ecosystems inside the forest. We have seen the effect of this in many places across Madagascar, and it results in many endemic aquatic insect species being replaced by widespread, nonendemic African fauna elements. Despite the presence of seemingly good forest streams (e.g., along circuit Imaitso) and ponds in the forest of Andringitra, the aquatic coleopteran fauna was somewhat disappointing. We did not find $H$. milloti here, neither in 2006 nor in 2013. The use of forests as a hiding place for zebus from cattle robbers might 
have been beneficial for the preservation of forest fragments in some regions of Madagascar as it served as a useful resource and therefore was not cut or burned. But from the point of view of maintaining a native endemic fauna in the streams and pools, zebu presence is not advantageous.

Finally, even in protected areas the conservation of invertebrate species requires specific considerations of the species of interest, as 'trickle-down' conservation is insufficient (Clark and May 2002; Jenkins et al. 2013). Concerted efforts for the specific conservation of $H$. milloti should be made, and it may even serve well as a flagship species for freshwater conservation on Madagascar. To aid in this, we propose the following common names for $H$. milloti, intended to awake interest in this species.

$\begin{array}{ll}\text { Malagasy } & \begin{array}{l}\text { Fandiorano fahagola [fandiorano }=\text { whirligig } \\ \text { beetle in official Malagasy dialect, } \\ \text { fahagola }=\text { old] }\end{array} \\ \text { English } & \begin{array}{r}\text { The Malagasy striped whirligig } \\ \text { French }\end{array} \\ \text { Swedish } & \text { Re gyrin malgache bariolé }\end{array}$

\section{ACKnowledgments}

R. Bukontaite, S. Holmgren, P. Perkins, and R. Sites are greatly thanked for their excellent companionship in the field during the 2014 Madagascar Expedition. Emmanuel Toussaint is thanked for his recommendation of the French common name. This project was funded in part by NSF DEB\#1402446 (PI K. B. Miller, Co-PI G. Gustafson) and \#DEB-1353426 (PI K. B. Miller). G. Gustafson is supported by a NIH IRACDA postdoctoral fellowship (5K12GM063651). J. Bergsten was funded by the Swedish Research Council (grants \#2009-3744, \#2013-5170), and the Royal Swedish Academy of Sciences.

\section{References Cited}

Altner, H., and R. Loftus. 1985. Ultrastructure and function of insect thermo- and hygroreceptors. Annual Review of Entomology 30: 273-295.

Bergsten, J., and K. B. Miller. 2007. Phylogeny of diving beetles reveals a coevolutionary arms race between sexes. PLoS ONE 2(6): e522.

Beutel, R. G., and R. E. Roughley. 2005. Gyrinidae Latreille, 1810 [pp. 55-64]. In: Handbuch der Zoologi/ Handbook of Zoology, Volume 1: Morphology and Systematics (Archostemata, Adephaga, Myxophaga, Polyphaga partim) (R. G. Beutel and R. A. B. Leschen, editors). Walter de Gruyter, Berlin, Germany.
Brinck, P. 1955. A revision of the Gyrinidae (Coleoptera) of the Ethiopian region. I. Lunds Universitets Årsskrift. N.F. Avd. 2 51(16): 1-144.

Chen, Y., M.-C. Shih, M.-H. Wu, E.-C. Yang, and K.-J. Chi. 2014. Underwater attachment using hairs: the functioning of spatula and sucker setae from male diving beetles. Journal of the Royal Society Interface 11:20140273. DOI: 10.1098/rsif.2014.0273.

Clark, J. A., and R. M. May. 2002. Taxonomic bias in conservation research. Science 297(5579): 191-192.

Evans, M. E. G. 1972. The jump of the click beetle (Coleoptera, Elateridae) - a preliminary study. Journal of Zoology 167(3): 319-336.

Folkerts, G. W. 1979. Spanglerogyrus albiventris, a primitive new genus and species of Gyrinidae (Coleoptera) from Alabama. The Coleopterists Bulletin 33(1): 1-8.

Jenkins, C. N., B. Guénard, S. E. Diamond, M. D. Weiser, and R. R. Dunn. 2013. Conservation implications of divergent global patterns of ant and vertebrate diversity. Diversity and Distributions 19: 1084-1092.

Legros, C. 1953. Un gyrinide nouveau de Madagascar (coléoptère). Naturaliste Malgache 5(1): 63-67.

Merivee, E., A. Must, A. Luik, and I. Williams. 2010. Electrophysiological identification of hygroreceptor neurons from the antennal dome-shaped sensilla in the ground beetle Pterostichus oblongopunctatus. Journal of Insect Physiology 56(11): 1671-1678.

Merivee, E., A. Ploomi, A. Luik, M. Rahi, and V. Sammelselg. 2001. Antennal sensilla of the ground beetle Platynus dorsalis (Pontoppidan, 1763) (Coleoptera, Carabidae). Microscopy Research and Technique 55: 339-349.

Merivee, E., A. Ploomi, M. Rahi, A. Luik, and V. Sammelselg. 2000. Antennal sensilla of the ground beetle Bembidion lampros Hbst (Coleoptera, Carabidae). Acta Zoologica (Stockholm) 81: 339-350.

Miller, K. B. 2003. The phylogeny of diving beetles (Coleoptera: Dytiscidae) and the evolution of sexual conflict. Biological Journal of the Linnean Society 79: 359-388.

Miller, K. B., and J. Bergsten. 2012. Phylogeny and classficiation of whirligig beetles (Coleoptera: Gyrinidae): relaxed-clock model outperforms parsimony and time-free Bayesian analyses. Systematic Entomology 37: 705-746.

Miller, K. B., and J. Bergsten. 2016. Diving Beetles of the World. Systematics and Biology of the Dytiscidae. John Hopkins University Press, Baltimore, MD.

Mittermeier, R. A., W. R. Turner, F. W. Larsen, T. M. Brooks, and C. Gascon. 2011. Global biodiversity conservation: The critical role of hotspots. [pp. 3-22]. In: Biodiversity hotspots: distribution and protection of conservation priority areas. (F. E. Zachos, and J. C. Habel, editors). Springer, Heidelberg, Germany.

Myers, N., R. A. Mittermeier, C. G. Mittermeier, G. A. B. da Fonseca, and J. Kents. 2000. Biodiversity hotspots for conservation priorities. Nature 403: 853-858. 
R Core Team. 2016. R: A language and environment for statistacal computing. R Foundation for Statistical Computing, Vienna, Austria. www.R-project.org (accessed 13 December 2016).

Steiner, W. E., Jr., and J. J. Anderson. 1981. Notes on the natural history of Spanglerogyrus albiventris Folkerts, with a new distribution record (Coleoptera: Gyrinidae). Pan-Pacific Entomologist 57 (1): 124-132.

Viette, P. 1991. Principales localités où des insectes ont été recueillis à Madagascar [Chief field stations where insects were collected in Madagascar]. Publié à compte d'auteur [published prviately by the author], Paris, France.

Walls, J. G. 1974. Distribution and recognition of United States whirligig beetles of the genus Gyretes (Coleoptera: Gyrinidae). Studies in Arthropoda 1 (1): 1-10.

(Received 20 February 2017; accepted 7 May 2017. Publication date 27 June 2017.) 